ORIGINAL ARTICLE

\title{
Panretinal photocoagulation laser in diabetic retinopathy patients
}

\author{
FARSHAD OSTADIAN ${ }^{1}$, FEREYDOUN FARRAHI ${ }^{2 *}$, BAHMAN CHERAGHIAN ${ }^{3}$, ALIREZA MAHDI NEJAD \\ ${ }^{1}$ Department of Ophthalmology, Infectious Ophthalmologic Research Center, Ahvaz Jundishapur University of Medical Sciences, Ahvaz, \\ Iran. ostadianfarshad@ajums.ac.ir \\ 2 Department of Ophthalmology, Infectious Ophthalmologic Research Center, Ahvaz Jundishapur University of Medical Sciences, Ahvaz, \\ Iran.feraidoonfarrahi@yahoo.com \\ ${ }^{3}$ Department of Biostatistics and Epidemiology, Ahvaz Jundishapur University of Medical Sciences, Ahvaz, Iran. \\ cheraghian-b@ajums.ac.ir \\ ${ }^{4}$ Department of Ophthalmology, Infectious Ophthalmologic Research Center, Ahvaz Jundishapur University of Medical Sciences, Ahvaz, \\ Iran. \\ mahdinejad.a@ajums.ac.ir \\ Corresponding Author: Fereydoun Farrahi \\ Tel: +989161111328
}

\begin{abstract}
Background: It was reported that corneal endothelial cell depletion is a complication of the retinal laser. In this study, the effect of panretinal laser on corneal endothelium was investigated. Method: A group consisting of 47 eyes of 47 Diabetic patients who need a panretinal photocoagulation laser was compared with another group of 47 diabetic patients who did not require a laser. The patient's age was chosen in the range of 50-70 and the tools included Ellex double frequency LASER, Specular microscopy, Pachymetry, and Condense Lens 90 . Time course of coefficient of variation, endothelial cell density, hexagonal cells and central corneal thickness were evaluated. ANOVA, Dennett's, and Mann-Whitney test was used to compare the data. P-value of $<0.05$ was considered statistically significant. Results: We found no significant differences in age, gender between the two groups. There was no significant differences in hexagonal cells, coefficient of variation, endothelial cell density and central corneal thickness between the two groups at any time points. Conclusion: This study suggests that the "panretinal photocoagulation laser" conserves corneal endothelial cells of subsequent damage in diabetic retinopathy patients
\end{abstract}

Keywords: photocoagulation laser, corneal, endothelial cell, argon laser, double frequency laser.

\section{INTRODUCTION}

Diabetes can have diverse impacts on several sections of the optic system. One can be visual disorders due to vascular and metabolic defects that can change the retina and the visual pathway. The formation of new vessels in the retina is the progress of retinopathy and causes proliferative diabetic retinopathy, so neovascularization happens in response to retinal ischemia, and new vessels grow on optical discs or elsewhere. Proliferative diabetic retinopathy (PDR) is the main cause of blindness in working-age adults and has affected many communities worldwide $(1,2)$.

Human corneal endothelial cells (HCECs) do not regenerate in vivo to a considerable point, holding in the G1-phase of the cell cycle(3). Panretinal photocoagulation laser (PRP) has been the standard remedy for patients with PDR since the 1970 (4). Although PRP reduces the risk of critical vision loss, its laser power can eradicate all retina layers such as ganglion cells and the retinal nerves, and hence cause visual field deficits. In such states, visual field testing can be lesser desirable to estimate the damage.(5). Speculator microscopy is an optical reflection microscope that reflects Slit light to the cornea and allows it to be viewed. The device is designed so that it does not allow the observation of non-specular light waves, so the image that is seen is exclusively related to the light waves that are reflected speculatively (6). Some of the characteristics of abnormal corneal endothelial cells include the following: cell count $<1500 \mathrm{cell} / \mathrm{mm}^{2}$, severe polymegatism, severe pleomorphism, presence of guttata, presence of any abnormal formation such as coalescence, an abnormal defect in a cell, wide area of severe edema, presence of bacteria or inflammatory cells and presence of ghost cells in the stroma. What is more common in people with diabetes is the increase in polymegatism, pleomorphism, and decreased cell hexagonally rate (7).

The laser beam needs to pass through anterior tissues such as the cornea, lens, and vitreous to reach the retina. The possibility of absorbing laser beam energy as it passes through the corneal tissue and damages the endothelial cells is predicted by a decrease in the number of cells, a decrease in the cells' hexagonally, or an increase in the thickness of the central part of the cornea(8-10). Due to the importance of corneal endothelium cells in maintaining corneal transparency, the laser beam's effect on corneal endothelium cells should be evaluated. Therefore, examining and comparing these cells before and after laser treatment can help clarify and provide other alternate methods for diabetic retinopathy if needed. This study aimed to compare variations in corneal endothelial cell indices with speculator microscopy examination before and after panretinal laser in diabetic retinopathy patients.

\section{MATERIALS \& METHOD}

Retinal photocoagulation typically involves using a laser pulse lasting $10-200 \mathrm{~ms}$, causing temporary hyperthermia several tens of degrees above normal body temperature. Currently, the most common laser used for photocoagulation is $\mathrm{Nd}$ : $\mathrm{YAG}=532 \mathrm{~nm}$ and Yellow semi conductive LASER $=577 \mathrm{~nm}$. The tools and equipment used in this research include Ellex double frequency LASER (Germany), Specular microscopy (SP 3000P), Pachymetry (Topcon. Japan), Condense Lens 90(volk.US). 
This investigation was conducted as an intervention (Quasi-experiments). A group consisting of 50 eyes of 50 Diabetic patients who require a panretinal photocoagulation laser was compared with another group of 50 diabetic patients who did not need a laser. The patient's age was selected in the range of 50-70 years, and the study was explained to all members, and written consent was obtained from them. The subjects had the right to leave the examination whenever they wanted. Age, gender, history of eye disease, family history, visual acuity with and without refraction using the Snellen chart, corneal examination, anterior chamber, iris lens and anterior vitreous with slit biomicroscopy lamp, retinal examination with 95 mark volk lenses, microscopic specular and central corneal thickness (CCT), was conducted for all participants. In all four stages of the patient's examination, the physician was the same. It was reassured that microscopic speculation is a noncontact method and would not cause any harm. Patients who have diabetic retinopathy and needed Panretinal laser photocoagulation were candidates for this treatment Patients with a history or active status of intraocular inflammation, patients with a history of any previous ocular surgery, patients with known Corneal endothelial Fuchs dystrophy, patients with known Iridocorneal endothelial syndrome, known Corneal opacity patients, patients with any glaucoma, Patients with reduced anterior chamber depth, who have used contact lenses in the past three months, who undergo intraocular surgery during these four months, who have previously undergone intraocular laser of any kind for any reason, Patients who have previously undergone photorefractive surgery, patients who have had an episode of corneal edema for any reason in their previous ophthalmology record, patients who have received an intraocular injection (in the anterior chamber or in vitro) of antibiotics, corton, ranibizumab or bevacizumab, were excluded from the study. In the current study, 3 patients were excluded from the study due to non-referral in one month after laser treatment, and for this reason, three patients were excluded from the control group.

\section{Statistics}

All statistical analyses were performed using SPSS 22. One-way analysis of variance (ANOVA) was performed for the analysis of the time course of changes with the Dunnett's test for multiple comparisons. The Mann-Whitney test was used to compare the data between the two groups. Unless otherwise indicated, the results are expressed as mean $\pm S D, p$ - value of $p<0.05$ was considered statistically significant.

\section{RESULTS}

Demographics of the study population are listed in Table 1. We found no significant differences in age $(p=0.43)$, gender $(p=0.63)$ between the two groups. Best corrected visual acuity at baseline is also shown in Table 1 and as you can see, in terms of the visions, the two groups are significantly different. In the control group, all patients had mild to moderate diabetic retinopathy who did not receive laser treatment. In the treatment group, 33 patients, $70 \%$, had Severe NPDR (non-proliferative diabetic retinopathy), and 14 patients, 30\%, had early PDR retinopathy.

Table 1 Demographics Features of the study population

\begin{tabular}{|l|l|l|l|l|}
\hline Demographic & Control Group & Treatment group & P value \\
\hline \multicolumn{2}{|l|}{ Age (mean \pm SD years) } & $60.6 \pm 4.97$ & $59.38 \pm 3.57$ & 0.43 \\
\hline Gender (\% female) & $20 / 600$ & 42.55 & 44.68 & 0.63 \\
\hline \multirow{3}{*}{$\begin{array}{l}\text { Best corrected visual } \\
\text { acuity BCVA (\%) }\end{array}$} & $20 / 400$ & 29.78 & 40.42 & \multirow{2}{*}{0.02} \\
\cline { 2 - 5 } & $20 / 300$ & 25.53 & 34.04 & \\
\cline { 2 - 5 } & $20 / 250$ & 29.78 & 23.4 & \\
\hline \multirow{3}{*}{ Diabetic Retinopathy (\%) } & Severe NPDR & & 2.12 & \\
\cline { 2 - 5 } & Early PDR & & 70 & \\
\cline { 2 - 5 } & Mild NPDR & 100 & 1629.89 & 199.78 \\
\hline
\end{tabular}

Time course of CV (coefficient of variation), ECD (endothelial cell density), HEX (hexagonal cells), and CCT (central corneal thickness) is shown in Table 2. The coefficient of variation was not statistically significant in control and treatment group $p=0.7$. There was no significant differences in hexagonal cells between the two groups at any time point's $p=0.8$. We found no significant differences in central corneal thickness $(p=0.4)$ and endothelial cell density $(p=0.2)$ between the two groups. We also detect no significant changes in coefficient of variation, endothelial cell density, hexagonal cells, and central corneal thickness 6 month after panretinal photocoagulation laser. 
Table 2. ECD, CV and percentage of HEX before and after times in control and treatment group

\begin{tabular}{|c|c|c|c|c|c|c|}
\hline Exam & Groups & Before PRP & After 1 month & After 3 months & After 6 months & $P$ value \\
\hline \multirow[b]{2}{*}{ HEX (\%) } & Control & $40.3 \pm 3.5$ & $40.2 \pm 3$ & $40.1 \pm 3$ & $40.3 \pm 3.2$ & \multirow[b]{2}{*}{0.8} \\
\hline & Treatment & $36.9 \pm 3.1$ & $36.4 \pm 3$ & $36.2 \pm 2.6$ & $36.3 \pm 2.9$ & \\
\hline \multirow{2}{*}{ CV (\%) } & Control & $37.6 \pm 1.9$ & $37.7 \pm 1.6$ & $37.6 \pm 1.5$ & $37.8 \pm 2.1$ & \multirow{2}{*}{0.7} \\
\hline & Treatment & $37.5 \pm 2.9$ & $37.9 \pm 2.9$ & $37.7 \pm 2.3$ & $37.6 \pm 3.0$ & \\
\hline \multirow[b]{2}{*}{ CCT } & Control & $556.1 \pm 13.4$ & $556.3 \pm 12.8$ & $555.4 \pm 10.5$ & $553.2 \pm 12.7$ & \multirow[b]{2}{*}{0.4} \\
\hline & Treatment & $551.6 \pm 15.8$ & $551.5 \pm 15.8$ & $551.7 \pm 15.9$ & $552.1 \pm 14.9$ & \\
\hline \multirow{2}{*}{$E C D_{\left(\text {cells } / \mathrm{mm}^{2}\right)}$} & Control & $2637 \pm 186$ & $2635 \pm 185$ & $2624 \pm 184$ & $2620 \pm 184$ & \multirow{2}{*}{0.2} \\
\hline & Treatment & $2771 \pm 176$ & $2770 \pm 168$ & $2779 \pm 161$ & $2774 \pm 173$ & \\
\hline
\end{tabular}

CV, coefficient of variation; ECD, endothelial cell density; HEX, hexagonal cells; CCT, central corneal thickness.

\section{DISCUSSION}

The current study evaluates if there is a correlation between panretinal photocoagulation laser and changes in the condition of corneal endothelial cells; it is tried to clarify whether changes in the density of endothelial cells occur due to panretinal photocoagulation laser: and in 6 months how are these changes? The number and hexagonal value of endothelial cells, the average Coefficient of Variation, and the mean cornea central thickness in laser group, during six months had no significant change.

Associated complications of panretinal photocoagulation were detected generally in the initial years of it. The frequent complications stated were choroidal detachment, exudative retinal detachment, anterior chamber narrowing, transient glaucoma, and ocular edema (11). Visual variations reported outright after panretinal photocoagulation include transient photophobia, impaired accommodation, and myopia. Reduced visual field and night vision deficiencies are typical subject magnitude (12, 13).

In the present study, our results demonstrated that the mean CCT loss was $0.36 \%$ in control group and increased $0.1 \%$ in treatment after 6 months indicating that panretinal photocoagulation laser provided a long-term safety in the term of CCT. Further the mean ECD loss was $0.64 \%$ in control and increased $0.1 \%$ in treatment after 6 months, indicating that panretinal photocoagulation laser provided almost long-term safety in the term of ECD and CCT. Previous investigations on the change in ECD after Lasers were summarized in Table 3 (10, 14-16).

Table 3. Previous studies reporting central ECD and CCT loss, CV and percentage of HEX after laser.

\begin{tabular}{|l|l|l|l|l|l|l|l|}
\hline Author(Year) & Eyes & Laser type & $\begin{array}{l}\text { Follow- } \\
\text { up }\end{array}$ & $\begin{array}{l}\text { Mean ECD } \\
\text { loss (\%) }\end{array}$ & $\begin{array}{l}\text { Mean CCT } \\
\text { loss (\%) }\end{array}$ & CV (\%) & $\begin{array}{l}\text { HEX } \\
\text { (\%) }\end{array}$ \\
\hline $\begin{array}{l}\text { Nurgul Ornek } \\
2018\end{array}$ & 18 & $\begin{array}{l}\text { Selective laser } \\
\text { trabeculoplasty }\end{array}$ & 1 Month & 1.3 & 0.22 & $\begin{array}{l}40.1- \\
37.9\end{array}$ & $54-57$ \\
\hline $\begin{array}{l}\text { Kanagaratnam } \\
2020\end{array}$ & 244 & $\begin{array}{l}\text { Selective laser } \\
\text { trabeculoplasty }\end{array}$ & 1 Month & 0.56 & +0.18 & $\begin{array}{l}38.5- \\
38.8\end{array}$ & $\begin{array}{l}50.3- \\
51.2\end{array}$ \\
\hline $\begin{array}{l}\text { Kanagaratnam } \\
2020\end{array}$ & 132 & $\begin{array}{l}\text { Retinal } \\
\text { photocoagulation } \\
\text { laser }\end{array}$ & 1 Month & 0.39 & +0.36 & $\begin{array}{l}38.1- \\
39.4\end{array}$ & $\begin{array}{l}50.6- \\
50.4\end{array}$ \\
\hline Pardos 1981 & 40 & $\begin{array}{l}\text { Argon laser } \\
\text { photocoagulation }\end{array}$ & $\begin{array}{l}1.5 \\
\text { Month }\end{array}$ & 2.7 & --- & --- & ---- \\
\hline $\begin{array}{l}\text { Trans corneal iridal } \\
\text { photocoagulation }\end{array}$ & 3 weeks & 1.2 & +4.5 & ---- & ---- \\
\hline $\begin{array}{l}\text { Panretinal } \\
\text { photocoagulation } \\
\text { laser }\end{array}$ & 6020 & 6 Month & +0.1 & +0.1 & $\begin{array}{l}37.5- \\
37.6\end{array}$ & $\begin{array}{l}36.9- \\
36.3\end{array}$ \\
\hline
\end{tabular}

CV, coefficient of variation; ECD, endothelial cell density; HEX, hexagonal cells; CCT, central corneal thickness.

The cornea's cellular stress levels are often indicated by the cell surface changes, such as the cells abnormally and the divergence from their hexagonal form $(17,18)$. We found no significant variations in morphologic parameters such as HEX or CV neither in control eyes nor in treatment eyes, suggesting that panretinal photocoagulation laser does not induce a notable change in polymegatism polymorphism even six months post-laser. Moreover, the
CV in our study was slightly higher, and the HEX was slightly lower than before the treatment. However, the information about CV and HEX should be described and interpreted by discretion and couldn't be accurately compared among methods employed in the current and previous studies. Pardos et al. 1981 stated that the mean ECD loss was $2.7 \%$ at six weeks after Argon laser photocoagulation (16). On the other similar to the present study, Kanagaratnam et al. 2020 revealed mean CCT increased 0.36 after one month after Retinal photocoagulation laser (15). 
Previously, it has been reported that argon laser photocoagulation decreases endothelial cell density (16, $19)$, whereas, in another study, retinal photocoagulation protected against endothelial cell damage (15). Kanagaratnam .et al in a cohort study, revealed that Retinal Photocoagulation seems to have a more limited impact on the corneal endothelium, with the only alteration of note an accretion in polymegatism among pre retinal photocoagulation and post retinal photocoagulation (15).

\section{CONCLUSION}

This study suggests that the "panretinal photocoagulation laser" conserves corneal endothelial cells of subsequent damage in diabetic retinopathy patients. It seems that performing argon panretinal laser, which is the most common type of retinal laser performed in diabetic patients, does not damage the number and hexagonally of corneal endothelial cells and does not change the CCT. This study was six months that cannot generalize this result for a long time, and probably more studies are needed.

\section{Acknowledgment}

This study is a part of the thesis of Alireza Mahdi Nejad and is financially supported by the vice-chancellor of research affairs of the Ahvaz Jundishapur University of Medical Sciences. The authors would like to thank Imam Khomeini Hospital members. Ethical approval was obtained from the Ethical Committee of Ahvaz Jundishapur University of Medical Sciences, and the ethical number is Ajums.REC.1393.223.

\section{REFERENCES}

1. Cheung N, Mitchell $P$, Wong TY. Diabetic retinopathy. Lancet (London, England). 2010;376(9735):124-36. Epub 2010/06/29. doi: 10.1016/s0140-6736(09)62124-3. PubMed PMID: 20580421.

2. Heng LZ, Comyn O, Peto T, Tadros C, Ng E, Sivaprasad S, et al. Diabetic retinopathy: pathogenesis, clinical grading, management and future developments. Diabetic medicine : a journal of the British Diabetic Association. 2013;30(6):64050. Epub 2012/12/05. doi: 10.1111/dme.12089. PubMed PMID: 23205608.

3. Liu Y, Sun H, Hu M, Zhu M, Tighe S, Chen S, et al. Human Corneal Endothelial Cells Expanded In Vitro Are a Powerful Resource for Tissue Engineering. Int $\mathrm{J}$ Med Sci. 2017;14(2):128-35. doi: 10.7150/ijms.17624. PubMed PMID: 28260988 .

4. Gonzalez VH, Wang P-w, Ruiz CQ. Panretinal Photocoagulation for Diabetic Retinopathy in the RIDE and RISE Trials: Not "1 and Done". Ophthalmology. 2019. doi: https://doi.org/10.1016/i.ophtha.2019.08.010.

5. Shimura M, Yasuda K, Nakazawa T, Abe T, Shiono T, lida T, et al. Panretinal photocoagulation induces pro-inflammatory cytokines and macular thickening in high-risk proliferative diabetic retinopathy. Graefe's archive for clinical and experimental ophthalmology $=$ Albrecht von Graefes Archiv für klinische und experimentelle Ophthalmologie. 2009;247:1617-24. doi: 10.1007/s00417-009-1147-x.

6. Hartmann C, Bergmann L. Specular microscopy: from speculative to spectacular microscopy. German journal of ophthalmology. 1996;5(6):496-503. Epub 1996/11/01. PubMed PMID: 9479545

7. Leelawongtawun $\mathrm{W}$, Suphachearaphan $\mathrm{W}$, Kampitak $\mathrm{K}$, Leelawongtawun R. A comparative study of corneal endothelial structure between diabetes and non-diabetes.
Journal of the Medical Association of Thailand = Chotmaihet thangphaet. 2015;98(5):484-8. Epub 2015/06/11. PubMed PMID: 26058277.

8. Hirst LW, Robin AL, Sherman S, Green WR, D'Anna S, Dunkelberger $\mathrm{G}$. Corneal endothelial changes after argonlaser iridotomy and panretinal photocoagulation. American journal of ophthalmology. 1982;93(4):473-81. Epub 1982/04/01. doi: 10.1016/0002-9394(82)90137-4. PubMed PMID: 7200328.

9. Azevedo B, Araujo RB, Ciongoli MR, Hatanaka M, Preti RC, Monteiro MLR, et al. The effect of panretinal photocoagulation on confocal laser scanning ophthalmoscopy and stereo photographic parameters of optic disk topography in patients with diabetic retinopathy. Arquivos brasileiros de oftalmologia. 2019;82(4):295-301. Epub 2019/05/01. doi: 10.5935/0004-2749.20190060. PubMed PMID: 31038552.

10. Chandler MJ, Moore PA, Dietrich UM, Martin CL, Vidyashankar A, Chen G. Effects of transcorneal iridal photocoagulation on the canine corneal endothelium using a diode laser. Veterinary ophthalmology. 2003;6(3):197-203. Epub 2003/09/03. doi: 10.1046/j.1463-5224.2003.00294.x. PubMed PMID: 12950650.

11. Reddy SV, Husain D. Panretinal Photocoagulation: A Review of Complications. Seminars in ophthalmology. 2017;33(1):83-8.

12. Liang JC, Huamonte FU. Reduction of immediate complications after panretinal photocoagulation. Retina (Philadelphia, Pa). 1984;4(3):166-70. Epub 1984/01/01. doi: 10.1097/00006982-198400430-00007. PubMed PMID: 6494634.

13. Yu PK, Cringle SJ, McAllister IL, Yu D-Y. Low power laser treatment of the retina ameliorates neovascularisation in a transgenic mouse model of retinal neovascularisation. Experimental Eye Research. 2009;89(5):791-800. doi: https://doi.org/10.1016/i.exer.2009.07.004.

14. Örnek N, Örnek K. Corneal endothelial changes following a single session of selective laser trabeculoplasty for pseudoexfoliative glaucoma. International ophthalmology. 2018;38(6):2327-33. Epub 2017/10/17. doi: 10.1007/s10792017-0730-0. PubMed PMID: 29030797.

15. Kanagaratnam A, Ong K. Quantitative and Morphological Corneal Endothelial Changes After Selective Laser Trabeculoplasty and Retinal Photocoagulation. Asia Pac J Ophthalmol (Phila). 2020;9(1):20-4. doi: 10.1097/01.APO.0000617912.85068.3b. PubMed PMID: 31990741.

16. Pardos GJ, Krachmer JH. Photocoagulation. Its effect on the corneal endothelial cell density of diabetics. Archives of ophthalmology (Chicago, III : 1960). 1981;99(1):84-6. Epub 1981/01/01. doi: 10.1001/archopht.1981.03930010086008. PubMed PMID: 7192979.

17. Cejka C, Cejkova J. Oxidative Stress to the Cornea, Changes in Corneal Optical Properties, and Advances in Treatment of Corneal Oxidative Injuries. Oxidative Medicine and Cellular Longevity. 2015;2015:591530. doi: $10.1155 / 2015 / 591530$.

18. Lin H, Li W, Dong N, Chen W, Liu J, Chen L, et al. Changes in Corneal Epithelial Layer Inflammatory Cells in Aqueous Tear-Deficient Dry Eye. Investigative Ophthalmology \& Visual Science. 2010;51(1):122-8. doi: 10.1167/iovs.093629.

19. Zhong J, Jia J, Yu J, Zhang L, Xiang Y. Preoperative photocoagulation reduces corneal endothelial cell damage after vitrectomy in patients with proliferative diabetic retinopathy. Medicine (Baltimore). 2017;96(40):e7971-e. doi: 10.1097/MD.0000000000007971. PubMed PMID: 28984756. 